\title{
Mulher, vida e liberdade: gênero, etnicidade e ecologia no movimento de mulheres curdas em Rojava ${ }^{1}$
}

\author{
FLÁVIA XAVIER MERLOTTI PANIZ
}

\section{Introdução}

Neste artigo apresentarei alguns resultados da pesquisa que venho desenvolvendo em meu doutorado, na qual busco compreender as articulações entre gênero, etnicidade e nação nas mobilizações produzidas pelos movimentos de mulheres curdas, no Oriente Médio. O objeto deste estudo, realizado entre 2016-2020, é a construção das campanhas internacionais produzidas por uma das organizações armadas de mulheres curdas, conhecida como $\mathrm{YPJ}^{2}$, em sua luta por autonomia territorial e política nos territórios reivindicados como curdos, a saber: Kobane, Afrin, Jazira e Região de Shabba, situados entre as fronteiras do Iraque, Irã, Síria e Turquia.

As campanhas internacionais de apoio aos movimentos de mulheres curdas ocorrem por meio da constituição de redes transnacionais composta por pessoas curdas e não curdas, homens e mulheres, em pelo menos 23 países, e que atuam, em diferentes âmbitos, em favor do reconhecimento político e da inserção dos movimentos de luta curda na agenda política global da comunidade internacional. As redes são compostas por organizações não governamentais de apoio a mulheres curdas, de mulheres em situação de violência, de apoio a minorias étnicas em luta por reconhecimento de seus territórios, de direitos humanos, imigrantes, refugiados etc.; por organizações criadas com fins específicos de construção da solidariedade

1 Este artigo é fruto de um texto originalmente apresentado no 41 $1^{\circ}$ Encontro Anual da Anpocs (2017) e das respectivas discussões produzidas no simpósio da pós-graduação de $\mathrm{n}^{\circ} 12$ (Ecologia e feminismo: criações políticas indígenas, quilombolas e camponesas), coordenado por Suzane de Alencar Vieira (UFG) e Fabiana Maizza (USP), a quem agradeço pela gentileza dos comentários e debates suscitados a partir dele.

2 As unidades de proteção popular curda são compostas pela Yekîneyên Parastina Jin, YPJ, que é o conhecido batalhão feminino das forças de resistência armada em Rojava, fundado em 2012, e pelo batalhão da unidade masculina das forças de resistência armada da região, chamado Yekîneyên Parastina Gel (YPG), fundado em 2004. Há, no entanto, diversas outras forças e batalhões atuando na região, em diversas frentes, como é o caso dos Peshmergas do Curdistão Iraquiano, os exércitos livres da Síria etc. 
ao movimentos de mulheres curdas, como Peace in Kurdistan, Kurdish Women's Rights Watch, Centre For Kurdish Progress, entre outros; por comunidades acadêmicas, compostas por pesquisadores e pesquisadoras do campo conhecido como Estudos Curdos, a saber, as kurdish societies, Kurdish Studies Network, Centro Europeu de Estudos Curdos, em Berlim, Instituto de Cultura Curda em Paris, entre outros; e ativistas em geral, que passaram a fundar e a atuar em diversos países por meio da criação dos mais de 40 comitês de solidariedade aos povos curdos, dois deles no Brasil (São Paulo e Porto Alegre).

Nessas redes circulam artigos, dados, notícias, livros, folders, imagens, vídeos, poesias, cartas e diferentes materiais elaborados pelas mulheres e homens das próprias organizações, por pesquisadores e pesquisadoras curdos e por ativistas da chamada "questão curda". Especificamente, o objeto de análise tem sido a circulação de ideias, objetos e materiais nessa rede e seus movimentos. Diante das impossibilidades de realização de trabalho de campo no Norte da Síria, uma vez que a região se encontra em guerra entre diferentes grupos (sendo o Isis ${ }^{3}$ um dos mais conhecidos internacionalmente), a pesquisa vem sendo realizada em duas etapas: a etnografia digital (2016-2019), que tem buscado compreender as dinâmicas de negociações das narrativas dos movimentos, as agendas e estratégias políticas dos variados grupos que se articulam conjuntamente nas redes sociais, nos grupos on-line e nos materiais que circulam nas plataformas digitais, e o trabalho de campo realizado com ativistas curdos e não curdos e organizações, situados na cidade de Londres, Inglaterra (2018-2019).

Neste artigo apresentarei reflexões sobre uma parte do material produzido e divulgado pelos próprios movimentos de mulheres curdas, que contêm as disputas das narrativas produzidas por elas em torno seu objetivo maior, que é a fundação de uma nação curda cujos pilares centrais são, segundo elas, a igualdade de gênero, ecologia, organização política horizontal, autônoma, baseada no consenso coletivo e marcada pela ausência de Estado. O objeto principal de análise deste texto é a carta conjunta produzida no evento chamado "Conferência ecológica dos povos da mesopotâmia", realizado na cidade de Van, em 2015. A carta é um dos primeiros objetos a apresentar as demandas ecológicas dessas minorias étnicas, possibilitando aqui uma reflexão sobre as relações entre gênero, etnicidade e ecologia, por meio da inserção do debate sobre as concepções de vida em seres considerados sencientes, humanos e não humanos, e os efeitos do antropoceno na vida dessas comunidades.

Neste texto, buscarei demonstrar como a articulação entre gênero, etnicidade e ecologia passou a ser mobilizada nas reflexões sobre a reorganização da vida produtiva e reprodutiva das comunidades, com base no seu lema central, Jîn, Jîyan e Azadî (mulher, vida e liberdade).

\section{Questão curda no século XX}

Atualmente, o território considerado como curdo abriga entre 25 e 35 milhões de pessoas e não é exclusivamente habitado por curdos. A depender da região, pode abrigar mais de oito etnias, falantes

3 Isis é a sigla referente a Islamic State of the Iraq and Syria, tradução inglesa da organização considerada terrorista, e que é conhecida no Brasil como "Estado Islâmico". Por respeito às comunidades muçulmanas, que não reconhecem essa organização como representativa do islã e seus pressupostos, utilizaremos a sigla conhecida como Daesh ou D’aish, que é oriunda da supressão de seu nome originalmente em árabe (aqui em grafia inglesa), ad-Dawlah al-Islämiyah fì 'l-『Iräq wa-sh-Shām. 
de kurmaji, gorani, persa, laki, farsi, árabe e adeptos de diferentes religiões, dentre elas o zoroastrismo e algumas vertentes de islã (Mojab 2011).

O conflito conhecido como "questão curda" teve origem no final do século XIX e início do XX. Com o fim do sultanato e a queda do Império Otomano, ao final da Primeira Guerra Mundial, acordos internacionais, conhecidos como tratados de Sykes-Picot (1916), Sèvres (1920) e Lausanne (1923), determinaram as redivisões dos territórios médio-orientais entre França e Inglaterra, que realizaram ocupações militares na região até o período das respectivas independências ${ }^{4}$. Como consequência desse processo, em 1923 foram fundados: a República da Turquia; a República Árabe da Síria, que se tornou independente da França em 1945; o Iraque, que se tornou independente da Inglaterra em 1958; e o Irã, que se constitui como uma república parlamentarista, tendo sofrido um golpe de Estado em 1953 e um contragolpe em 1979, que deu origem à fundação da República Islâmica do Irã (Kowarsch \& Kilic 2007: 21$)^{5}$.

Nesse contexto, os territórios considerados curdos foram divididos entre estes países e também uma porção da Armênia, e desde então diferentes formas de resistência e luta se organizam na região, configurando a chamada "questão curda" (Bozarslan 1997: 23).

Com relação às narrativas desse conflito, venho elaborando ao longo da pesquisa um debate sobre como as categorias são operadas historicamente, por exemplo: no contexto da formação dos Estados nacionais, o principal argumento, mobilizado pelos governos da Turquia e da Síria, utilizado para questionar o pertencimento curdo às suas terras teria sido a exigência de documentos que comprovassem que eles já viviam nos territórios antes das formações dos próprios Estados, ou seja, antes de 1945 (Yildiz 2008). Como não possuíam esses documentos, os curdos perderam cerca de um milhão de hectares. Desde então a noção de ancestralidade, entendida como unidade simultânea entre etnicidade, territorialidade (espaço) e temporalidade, ou seja, um povo que habita uma terra específica há um período considerável de tempo e que compartilha de uma comunidade comum marcada por elementos culturais, passa a ser mobilizada como forma de provação de pertencimento histórico dos povos curdos à terra.

Com a declaração do princípio de autodeterminação dos povos ratificada pela ONU, a partir dos anos 1950 as categorias etnicidade e territorialidade, que compõem uma noção mais ampla de ancestralidade, tornam-se parte da estratégia política de luta por autonomia dos povos curdos para reconhecimento de sua terra, compondo uma série de narrativas de luta por provação do direito à independência ao longo do século XX (Bozarslan 2007; Romano 2006; Gunes 2012). A contribuição analítica deste

\footnotetext{
4 A Coleção Elphinston (sobre as ocupações inglesas no Iraque na primeira metade do século XX) pertence ao arquivo do Centro de Oriente Médio do Colégio Saint Anthony da Universidade de Oxford. Os documentos foram produzidos pelo coronel W. G. Elphinston, oficial do serviço de inteligência britânica para o Oriente Médio, que atuou na região da Jazira entre 1918 e 1919, tendo sido também membro da missão britânica armada no Iraque entre 1925 e 1928 e da brigada Quillian, no Cairo, que participou da campanha contra Rashid Ali al-Kailani no Iraque e da ocupação britânica na Síria e no Líbano durante a Segunda Guerra Mundial. O documento completo do Tratado de Sèvres (publicado em inglês) foi encontrado na sessão de documentos históricos do acervo digital do Centro de Pequisa e Implementação de Estudos Estratégicos da Universidade de Baskent (Baskent-SAM), Turquia, e pode ser acessado no link: http://sam.baskent.edu.tr/belge/Sevres_ENG.pdf (acessado pela última vez em 23 de julho de 2018).

5 Sobre a partilha dos territórios curdos: "Três dos quatro Estados que governam o Curdistão - Turquia, Iraque e Síria - são produtos do desmantelamento do Império Otomano no despertar da Primeira Guerra Mundial. Ao mesmo tempo em que a República Turca herdou um pedaço do Império Otomano, Grã-Bretanha e França criaram Iraque e Síria a partir de províncias à Sudeste do Império quando derrotaram o sultanato Turco em 1917-1918. O resultado foi uma redivisão dos curdos entre quatro países com um pequeno enclave na União Soviética" (Mojab 2001: 6), tradução minha.
} 
artigo consiste justamente em demonstrar como gênero e ecologia emergiram como categorias de resistência e estratégia política dos movimentos por autonomia no Curdistão, na passagem do século XX para o XXI.

O protagonismo das mulheres curdas e a inserção da igualdade de gênero no debate nacional Segundo os estudos realizados por Martin Heper, nos anos 1970 diversos grupos e partidos políticos foram fundados em Ankara, capital da Turquia, dentre eles, um núcleo de jovens que se consideravam de esquerda, e que teria fundado o Partido dos Trabalhadores curdos, conhecido como PKK. Dentre seus fundadores, estava o ativista curdo e cientista político Abdullah Öcalan, que desde 1999 encontra-se preso na Turquia. A agenda política do PKK, que naquela época se reivindicava como um partido de orientação marxista-leninista, incluía a luta por conquista de direitos para as comunidades curdas, como o direito de reconhecimento institucional, direito de poder se expressar em kurmanci, a luta por autonomia na região da Anatólia e, por conseguinte, a retomada do controle político dos territórios curdos. Com a ascensão dos conflitos e narrativas de violência produzidas pelo Estado turco, o PKK tornou-se um movimento de guerrilha armada que protagonizava a resistência e a luta por autonomia curda no Sudoeste do país nessa década (Heper 2007: 114).

Discordantes dos modos de condução das pautas, das agendas políticas e também questionando as próprias divisões e atribuições entre homens e mulheres no interior do PKK, em 1987 as militantes curdas fundaram a Patriotic Women Union of Kurdistan (YJWK), que posteriormente mudou de nome para Free Women's Movement of Kurdistan (Tajk) (Dryaz 2011). Na década seguinte, outras duas organizações de mulheres foram fundadas, Union of the Free Women of Kurdistan (Yjak), 1995, e Women Worker's Party of Kurdistan (PJKK), 1999. A formação dos diferentes grupos de mulheres simboliza o alcance do ativismo produzido por elas e a multiplicidade de perspectivas presentes nos movimentos. Guardadas as especificidades de cada uma delas, em linhas gerais as denúncias de posturas machistas por parte de seus companheiros de militância, e de violência específica de gênero por parte das forças militares armadas do Estado turco, as mulheres passaram a elaborar suas próprias pautas. Nesse contexto, a busca pela simetria das relações de poder entre gênero e etnicidade no interior dos movimentos de autonomia e libertação curda foi sendo elaborada coletivamente. Segundo Mojab (2011), a mobilização da igualdade de gênero no interior da própria luta foi a forma encontrada por elas de colocar a liberdade das mulheres como elemento constitutivo da agenda nacional comum e contestar a militância tradicional dos homens, que projetava a liberdade das mulheres para o horizonte pós-guerra e pós-autonomia.

Segundo Dryaz (2011), Kesire Yildrim, membro do comitê central do PKK e esposa de Abdullah Öcalan, teria influenciado as transformações e posicionamentos políticos de seu marido em relação ao movimento de mulheres. Öcalan é até hoje considerado uma das principais lideranças políticas e intelectuais do movimento de autonomia curda, e sua mudança de perspectiva em torno da pauta da igualdade de gênero teria sido fundamental no tensionamento da luta pela simetria das relações de poder entre liberdade das mulheres e liberdade nacional e étnica curda nos anos 1980. Mas foi a partir dos anos 1990 e 2000 que se tornou possível observar mais claramente o reflexo da mobilização das mulheres curdas no interior do partido. Essa mudança de posicionamento político passou a ser reelaborada no 
conjunto da militância organizada por homens e por mulheres, a partir de um processo de cooperação mútua, e esse movimento aparece também nas obras recentes do próprio Öcalan, como As raizes da civilização (2007), Guerra e paz no Curdistão: perspectivas para uma solução política para a questão curda ([2008]2011), Confederalismo democrático (2011), Manifesto por uma civilização democrática (2015) e Libertando a vida: a revolução das mulheres ([2016]2018).

Um dos resultados da análise do material analisado no curso da pesquisa indica também que foi a partir dos anos 2000 que as mulheres curdas da Turquia e da Síria, que já protagonizavam o movimento de luta e resistência às ações de grupos terroristas da região e da violência e marginalização promovida pela exclusão e ataques por parte dos Estados locais, passaram a ter maior visibilidade, inclusive midiática. O maior destaque da atuação das mulheres na mídia e nas redes sociais ocorreu a partir do movimento de luta armada conhecido como YPJ, o batalhão feminino de guerrilha armada fundado em meados de 2012, e que tinha como propósito inicial fazer frente aos avanços de grupos como o Daesh e retomar o controle dos territórios curdos. Hoje, 2019, segundo as informações oficiais divulgadas pela YPJ, nos territórios considerados autônomos a igualdade de gênero tornou-se a base da construção política comunitária.

Qualificando o debate: igualdade de gênero e as noções de mulher, vida e liberdade

Com base em documentos como a Declaração final da Primeira Conferência ecológica dos povos da Mesopotâmia, o documento conhecido como "Contrato Social de Rojava", nas declarações elaboradas pelos movimentos e partidos de mulheres curdas, como o Komalên Jinên Kurdistan, o YPJ, o Kongreya, e o $T E V$-Dem, e na literatura produzida no campo de Estudos curdos sobre ecologia, gênero e confederalismo democrático, apresentarei, então, como gênero e ecologia passaram a ser categorias negociadas e constitutivas da agenda política curda. Buscarei sintetizar o que vem sendo entendido por igualdade de gênero e como esse debate está sendo constituído no seio da militância, uma vez que a luta por autonomia das mulheres perpassa pela revisão dos papéis e das relações concebidas por elas como tradicionais de gênero na vida social e política, como a ampliação e reconhecimento da participação política das mulheres, reordenamento das relações familiares, laborais etc. Por fim, concluirei apresentando como o papel cumprido pelas mulheres nesse processo pretende reconfigurar os modos de organização da vida no interior das próprias comunidades, por meio do conhecido lema Jîn, Jîyan e Azadî̀ (mulher, vida e liberdade) (Flach 2007; Mojabi 2001: 71; Al-Ali \& Pratt 2011: 337).

O encontro de conferência ecológica dos povos da mesopotâmia foi realizado entre os dias 24 e 25 de abril de 2016, na região de Van. O documento foi produzido em conjunto com as diversas organizações que compõem o movimento, como o Movimento Ecológico Mesopotâmico (MEM), revista Gaya,

\footnotetext{
6 As informações sobre a origem desse documento são desencontradas. Uma das possibilidades é de que tenha sido formulado por membros do conselho da organização chamada Peace in Kurdistan (PIK). Outra narrativa possível é de que houve uma ação conjunta dos membros do Partido da União Democrática (PYD), dos membros do conselho nacional curdo e do comitê superior curdo para proclamar autonomia dos territórios de Rojava, Afrin, Kobane e Jazira. Esse acordo teria previsto também a organização de um comitê para formular documentos da transição dos territórios, tendo como resultado desse trabalho o Contrato Social de Rojava, que pode ser acessado no link: https://peaceinkurdistancampaign.files.wordpress.com/2014/03/english-version_sc_revised-060314.pdf
} 
municipalidade de Dersîm-Ovacik, Rebelião do Mar Negro, Defesa das florestas do Norte, Campanha pelo direito à água, e representantes de organizações políticas como o Congresso da Sociedade Democrática (DTK), Mulheres Livres do Curdistão (KJA), Congresso Democrático Popular (HDK) e Partido Democrático Popular da Turquia (HDP). Ao todo 170 pessoas participaram do evento, que teve como pauta a elaboração de uma agenda política para "evitar a destruição física, ideológica e mental das energias, águas, florestas, solos, cidades, agriculturas e tecnologias e promover a construção de uma nova vida”.

A noção de vida que aparece no documento tem sido mobilizada em diferentes textos divulgados pelas organizações curdas e no debate intelectual curdo. Esse movimento organiza-se principalmente como forma de organizar nas comunidades rurais curdas a resistência a processos de remanejamento ambiental na região da Anatólia, como o Projeto do Sudoeste da Anatólia (GAP), Ilisu Dam, Munzur dams, Green Way, Cerattepe Mining e Kanal Istanbul, que, de acordo com o documento da Declaração, "promovem o desmatamento das florestas, comercialização das águas, transformação da terra em commodity e controle da natureza e da população alienando as pessoas de suas formas originárias de vida”.

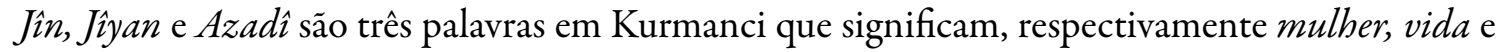
liberdade. De acordo com os textos produzidos e divulgados pela organização Komalên Jinên Kurdistan, essas três palavras representam uma homenagem à memória das ativistas Sakine Cansiz, Fidan Dogan e Leyla Saylemez, mas elas são também mobilizadas como pilares que orientam a organização da recente luta por autonomia.

Para além da constituição de uma resistência aos avanços do Daesh e dos respectivos Estados locais em seus territórios, o movimento de resistência nas comunidades curdas situadas ao Norte da Síria vem construindo sua luta política com base no chamado confederalismo democrático, modelo político elaborado por Abdullah Öcalan. O confederalismo democrático (Öcalan, 2016) possui como proposta central a conformação de uma organização política que atenda às demandas das diferentes comunidades curdas em seus territórios, respeitando as configurações sociais, religiosas, políticas e culturais ali estabelecidas. O discurso de Öcalan, endossado pelos demais movimentos de liderança na região, defende que a concepção de Estado, tal qual como lhes foi imposto no processo de colonização no início do século XX, provocou uma ruptura nas organizações tradicionais locais, ocasionando conflitos internos na região, que facilitou a exploração do petróleo para exportação e rompeu com as estruturas estabelecidas de organização econômica e familiar curda. Segundo Öcalan, Estado, capitalismo e patriarcalismo (expressões utilizadas por ele) são concepções políticas que não podem ser pensadas de forma separada, pois elas possuem uma relação de codependência, que no caso de países marcados pela colonização, não acompanha a estrutura de bem-estar, como ocorre nos Estados do Norte da Europa, mas sim uma estrutura de exploração da terra, do trabalho e dos corpos dessas pessoas. Para ele, o confederalismo democrático propõe uma organização nacional curda sem fronteiras e sem Estado, intermunicipal, e, em suas palavras, não seria possível imaginar uma nação curda sem Estado se não houvesse, ao mesmo tempo, uma ruptura com o respectivo "ordenamento sexista e exploratório demandado por essa forma de organização". Dessa maneira, o confederalismo democrático seria, segundo ele, o modelo político capaz de alinhar as demandas de uma organização comunitária municipalista transfronteiriça, orientado por 
uma perspectiva ecológica de produção e reprodução da vida e, principalmente, fundado na igualdade de gênero.

O alinhamento em torno dos sentidos que envolvem as categorias Mulher, vida e liberdade se torna ponto central para a compreensão dessa reflexão. A análise do material indica que as três categorias são inseparáveis e são pensadas de formas correlacionadas e interconectadas. A centralidade da mulher na ocupação de cargos políticos para a promoção da igualdade de gênero é mobilizada com base no argumento (de Öcalan e das organizações de mulheres) de que historicamente cargos políticos e poderes decisórios foram ocupados por homens, e que às mulheres coube uma luta histórica para promover o exercício de seus direitos por meio do convencimento constante de suas demandas.

A campanha coletiva das mulheres por reorganização da ideia de vida passa por muitos aspectos, um deles é a educação e a ciência para a liberdade, uma vez que a igualdade de gênero precisa ser integrada como parte constitutiva da vida pública e coletiva. Assim, no primeiro semestre de 2017 foi fundada a primeira academia de Jineologî, que seria um centro de pesquisa dedicado a compreender a conformação de uma epistemologia científica fundada na experiência das mulheres curdas. Nos dias 23 e 24 de setembro de 2017, na cidade de Buenos Aires, foi promovido o $1^{\circ}$ Encontro de Jineolojî da América Latina, com um workshop ministrado por duas militantes curdas.

Como mulher, vida e liberdade são concepções integradas, interconectadas e que não podem ser pensadas separadamente, a concepção de vida, por sua vez, diz respeito às diferentes formas de organização da vida produtiva e reprodutiva, diz respeito à organização do trabalho, sua relação com a terra, com o meio ambiente, das novas formas de organização dos trabalhos entre homens e mulheres e, portanto, com uma promoção de novas perspectivas da ideia de temporalidade e de defesa da vida coletiva. Por exemplo, a constituição de uma economia local, cuja exploração é controlada, como no caso das duas refinarias de petróleo, na produção em larga escala de sabão, materiais de construção, ou o cultivo de trigo, cevada e a criação de gado. A sustentabilidade econômica é compreendida como uma forma de organização coletiva e descentralizada, com foco na preservação ambiental, na vida humana e não humana e organizada por meio de cooperativas, mas não necessariamente destinadas exclusivamente à autossubsistência. Há um dissenso sobre a proposta de coletividade da terra. Apesar de o documento do MEM defender a propriedade coletiva, no Norte da Síria as propriedades são privadas, e se estabeleceu uma margem-limite de lucro, cujo excedente é revertido para as organizações que administram as municipalidades.

A noção de liberdade, por fim, seria a expressão cultural, política, social, econômica, intelectual e religiosa das diferentes comunidades curdas, integrada pelas duas anteriores. Isto é, a liberdade seria uma consequência e também um horizonte na busca pela igualdade de gênero e pela estruturação de uma noção específica de vida, humana, não humana e da terra. Em suma, não haveria vida sem mulheres, e não há mulheres sem liberdade; assim, o projeto de liberdade nacional curda deve ser constituído pela experiência e pela perspectiva daquilo que mulheres e homens entendem como tal. E também assim, a liberdade representa a própria conquista interna de autonomia. Em conjunto, Jîn, Jîyan e Azadî simbolizam a igualdade de gênero, a perspectiva ecológica específica das comunidades curdas e a conformação de uma nação transregional, transfronteiriça e sem Estado. 
Em termos de organização política, os territórios já considerados como autônomos são administrados pelo TEV-DEM (Tevgera Civaka, Demokratik), uma espécie de aliança democrática formada em 2012. O TEV-DEM, por sua vez, estabeleceu a criação dos conselhos populares, que são os espaços locais de organização comunitária, que a depender do arranjo social estabelecido pode variar entre $20 \mathrm{e}$ 200 pessoas. Para garantir a igualdade de gênero nas organizações comunitárias, segundo elas, há uma exigência mínima de participação de homens e mulheres (não há indicação sobre cis ou trans na literatura sobre o tema) e uma cota de $10 \%$ para demais minorias étnicas não curdas da região. Há outros órgãos de administração como o Supremo Conselho Curdo (SKC) e a Autoadministração Democrática (DSA), que possui coocupação de cargo por gênero e rege os 22 ministérios locais.

Diante da compilação resumida dessas três categorias, há muitos caminhos analíticos possíveis, sobretudo na interface entre gênero e nacionalismo. Neste texto concentro-me apenas nas formas como elas estão conectadas. Os debates sobre gênero, etnicidade e ecologia na proposta elaborada pelas lideranças curdas aproxima-se em alguma medida do debate realizado a partir dos estudos de algumas populações indígenas da América Latina, apontando para o mesmo caminho: maneiras distintas de estabelecer relações com a Terra e com o meio ambiente a partir da reconfiguração da ideia de vida, orientados por parâmetros não desenvolvimentistas de produção e reprodução da vida cotidiana.

A recente retomada da perspectiva ambiental nas Ciências Sociais trouxe uma nova perspectiva para questões metodológicas das pautas do ecofeminismo. A reconfiguração da pauta ecológica, no caso das comunidades curdas, vai além da junção de pauta de preservação ambiental às demais pautas de luta das comunidades nativas como demarcação de terras e acesso a direitos reconhecidos. Assim como o debate sobre racialização, inserido (não somente, mas principalmente) pelas feministas negras propõe, entre outras coisas, a restruturação das categorias analíticas de gênero que incorporem as experiências das mulheres negras para produzir uma nova agenda de reflexão conjunta e que tragam à tona os debates sobre como as conexões entre as categorias são produzidas (interseccionalidade, multiposicionalidade, consubstanciação, adição etc.); ecologia e questões ambientais também veem buscando, nesse mesmo caminho, o alargamento de categorias analíticas de gênero e etnicidade que possam incorporar as demandas de diversas minorias étnicas a partir da compreensão do manejo de suas próprias vidas. Nesse sentido, a noção de vida assume a relevância central para a compreensão de suas pautas.

A discussão sobre colonialidade de gênero, conforme apresentada por María Lugones (2014), revela que os caminhos rumo ao feminismo decolonial não se limitam a retratar as diferenças das perspectivas de gênero a partir de uma desomogeneização das experiências que a circunscrevem, mas tratam-se de refletir sobre cosmologias, maneiras distintas de percepção e organização da vida no sentido mais amplo do termo. E de perspectiva analítica não se trata somente de incorporar essas pautas para a ampliação e reconhecimento das limitações dos feminismos reconhecidos tradicionalmente como hegemônicos, ou produzidos a partir das experiências e do trabalho intelectual de mulheres, intelectuais, heterossexuais, cis, brancas, europeias etc., mas de possibilitar a existência do outro a partir da abdicação de privilégios limítrofes para ambas as vidas. O que está sendo apontado é que há uma disjunção entre o modo desenfreado de crescimento industrial e exploração de recursos naturais que o sustentam e as formas de organização da vida de minorias étnicas não inseridas nesse projeto global de modernidade 
ocidental dos grandes centros urbanos. Reconhecer essa disjunção não seria, então, suficiente para torná-la menos problemática, mas abdicar de seus privilégios seria ao menos um passo inicial.

$\mathrm{O}$ atual diagnóstico do estado de degradação da Terra indica que a redução drástica da exploração e degradação ambiental seria o único caminho possível para evitar a destruição sistemática de minorias étnicas.

A produção do cotidiano dentro do qual uma pessoa existe produz ela mesma, na medida em que fornece vestimenta, comida, economias e ecologias, gestos, ritmos, habitats e noções de espaço e tempo particulares, significativos. Mas é importante que estes modos não sejam simplesmente diferentes. Eles incluem a afirmação da vida ao invés do lucro, o comunalismo ao invés do individualismo, o "estar" ao invés do empreender, seres em relação em vez de seres em constantes divisões dicotômicas, em fragmentos ordenados hierárquica e violentamente (Lugones 2014: 949).

A aproximação que possibilita o diálogo entre os debates antropológicos em torno do antropoceno e dos feminismos pós-coloniais na América Latina e no Curdistão reside no encontro da reflexão sobre diferentes formas de produção e reprodução da vida. Isto é, implica reconhecer que as diferentes formas de vida e existência na Terra dependem basicamente de recursos naturais de formas distintas, de modo que uma das formas de exercício de poder de um povo sobre outro é deslegitimá-los por meio da degradação ambiental que impede a produção e reprodução dessas vidas, no caso, tomando as palavras de Abdullah Öcalan, que os "Estados capitalistas modernos historicamente submetem às minorias étnicas".

\section{Antropoceno como categoria política e analítica e a noção de "bom viver"}

Há uma vasta literatura sobre a constituição dos debates em torno do antropoceno, e aqui me detenho a uma definição até mesmo simplista do tema, que é a classificação geológica, que indica a idade da Terra a partir da identificação histórica do estado dos recursos ambientais, realizada conjuntamente em quatro frentes: geologia, arqueologia, biologia e engenharia de ecossistemas (Coombs 2014). Os debates geopolíticos em torno do antropoceno apontam, em diferentes medidas, o estado catastrófico da atual escassez de recursos ambientais e a crise da biodiversidade causada pela ação humana na natureza. Nas ciências sociais brasileiras esse debate tem sido mobilizado principalmente pela etnologia que, ancorada nos diálogos sobre cosmologia ameríndia, propõe novas formas de compreensão do modo como se estabelece as relações entre humano/não humano/corpo/cultura/terra/natureza, e tratou de estabelecer a crítica política da escassez de recursos ambientais responsabilizando, no Brasil, o agronegócio pela intensificação do genocídio dos povos indígenas em sua luta por direito à Terra (Viveiros de Castro 2010).

Nesse contexto, o debate em torno do antropoceno passa de uma classificação geológica da Terra (em contraposição ao holoceno), para transformar-se em categoria analítica e de disputa política, cujo embate é ancorado na sustentação das múltiplas formas de vida, capaz de indicar que embora todos os 
humanos dependam de recursos naturais, diferentes formas de organização de vida indicam a intensidade dessa dependência de forma mais direta, e projeta maior força política no argumento de que as grandes potências globais detêm o poder e controlam à revelia de suas próprias necessidades industriais a política de exploração ambiental global.

A luta por direito à Terra, no sentido planetário mesmo do termo, estabelece parâmetros que vão muito além da disputa territorial, porque dizem respeito ao modo como os recursos ambientais são geridos. A denúncia da exploração compulsória da biodiversidade, desmatamento, agronegócio, monocultura de mercado, criação de gado em massa, escassez de recursos hídricos, controle de produção e reprodução da vida humana e não humana, a hierarquização dos seres viventes (chamado de especismo) destacam a principal crítica da perspectiva política da era do antropoceno, que é o etnocentrismo e a centralidade do humano material no manejo da própria ideia de vida. $\mathrm{O}$ enquadramento geopolítico desse debate revela que não se trata de qualquer humano, mas daqueles que habitam os grandes centros industriais que dependem e disputam petróleo, água, recursos minerais etc., ou das potências globais.

A politização dos debates sobre o antropoceno tem sido um importante recurso estratégico do contato entre os debates das ciências sociais com os debates sobre as questões ambientais; primeiro porque estruturam-se argumentos analíticos para combater politicamente a ordem vigente da gestão de recursos ambientais, travando um debate entre ambientalistas e os chamados "negacionistas" (aqueles que se negam a reconhecer o desastre ambiental e climático contemporâneo) (Costa 2014); segundo, porque estabelece novas categorias de luta para os movimentos sociais, colocando a própria noção de vida como perspectiva política e que tem sido traduzida recentemente por meio da luta pelo buen vivir (bom viver). ${ }^{7}$

O presente etnográfico não é de modo algum um "tempo" imóvel; as sociedades lentas conhecem velocidades infinitas, acelerações extra-históricas, em uma palavra, devires, que fazem do conceito indígena do vivir bien algo metafisicamente muito mais parecido com um esporte radical do que com uma descansada aposentadoria campestre (Danowski; Viveiros de Castro 2014: 93).

A perspectiva do bom viver tem sido pauta de discussão nos movimentos de mulheres afro-ameríndias na América Latina, que passam justamente a contestar o manejo dos recursos naturais em suas comunidades por parte dos Estados nacionais, sobretudo terra e água, estabelecendo uma política de defesa da vida a partir de um registro de retomada da perspectiva da ancestralidade, ou retorno às raízes na forma de reordenamento da vida cotidiana trazendo à tona etnicidade, gênero e ecologia. Não se trata somente de manutenção da existência vital, mas de viver dignamente, com direitos étnicos e políticos respeitados e disposição de recursos necessários à vida justa no modo como lhes aprouver. Cito abaixo o trecho de um artigo resultado de estudo realizado com o movimento de mulheres negras do Alto Cauca, na Colômbia, e que sintetiza o argumento que busco apresentar:

7 Lugones também apresenta a ideia de "buen vivir". Diz ela: "A nova constituição boliviana, o governo de Morales e os movimentos indígenas de Abya Yala expressam um compromisso com a filosofia de suma qamaña (frequentemente traduzido como 'bem viver'). A relação entre qamañae utjañaindica a importância da complementarida de e sua inseparabilidade do florescimento comunal na produção constante de equilíbrio cósmico." (Lugones 2014: 944). 
El territorio es para las comunidades negras, en especial para las mujeres, el espacio para ser, en comunión y continuidad con la naturaleza, con el agua. Potencia su realización como humanos/ as en alegría, paz y libertad. Tener un territorio, sentirse perteneciente a éste y a una comunidad y poder dejar algo para los renacientes significa tener autonomía para movilizarse; disfrutar de un ambiente sano con la capacidad de retribuirlo con el cuidado; ejercer la minería ancestral garantizando la existencia del río y del oro, como posibilidad de trabajo fuera de las lógicas de acumulación; indica la posibilidad de vivir sin miedos, amenazas, violencias y discriminación; tener alegría y capacidad de disfrutar la vida. Estos son componentes del bienestar del proyecto de vida colectivo que se traducen en lo que desde algunas perspectivas se viene denominando buen vivir como propuesta contrahegemónica al desarrollo. Las mujeres afirman en sus arengas: "[...] el territorio es la vida y la vida no se vende, se ama y se defiende", "batea sí, retros no" (Mina; Escobar; Machado; Botero 2015:173).

Os diálogos entre as teorias sobre o antropoceno e de alguns dos debates em torno dos feminismos pós-coloniais, decoloniais e descoloniais (guardadas as respectivas diferenças entre essas categorias) é estabelecido sobretudo a partir da crítica da hierarquização da vida dos recursos naturais, hierarquização das espécies e dos próprios seres humanos. Em síntese, o exercício das formas de controle produtivo e reprodutivo que estabelecem parâmetros de controle humano sobre a natureza partiriam dos mesmos princípios das formas de controle do humano sobre os animais e de humanos sobre outros humanos (colonizados, racializados e generificados), por intermédio do controle do Estado sobre o corpo. Na perspectiva de Lugones, trata-se de uma nefasta consequência do colonialismo, que não tratou apenas de colonizar terras, mas de pessoas, de modos de vida em geral, hierarquizando as vidas que valem e as que não valem, e que portanto são dignas de obterem recursos, daquelas que não o são. Dessa perspectiva, a ressignificação da ideia de bom viver incorpora estreitamento sensitivo da ideia de vida da Terra e vida humana, de forma que qualquer forma de violência sobre um incide e afeta diretamente sobre o outro.

\section{Questão ambiental e a centralidade do humano na base da luta por direitos}

Tratando de não essencializar ou romantizar o tratamento da questão, faz-se necessário dizer que há dissenso, encontros e desencontros entre diversos movimentos políticos nesse debate. Trago como exemplo de mostra do dissenso, algumas diferentes perspectivas do debate sobre os direitos dos animais.

A discussão sobre hierarquização das espécies e direitos dos animais remonta, mais uma vez, à própria ideia de pela ação humana na natureza. Dentre os diversos movimentos de defesa dos animais, há uma ponte entre veganismo e feminismo, que parte, sobretudo, da crítica ao exercício de biocontrole sobre animais e mulheres com ênfase na retórica de animalização das mulheres como estratégia de exercício de poder, desde o parto, onde na conformação de um léxico concentrado a partir da categorização das espécies mamíferas, na comensalidade, no vocabulário e por meio de exercícios de adjetivação de mulheres e minorias étnicas, transformando a todos em animais e, portanto, passíveis de serem controlados ou exterminados, como adverte a própria María Lugones. 
Ver a colonialidade é ver a poderosa redução de seres humanos a animais, a inferiores por natureza, em uma compreensão esquizoide de realidade que dicotomiza humano de natureza, humano de não humano, impondo assim uma ontologia e uma cosmologia que, em seu poder e constituição, indeferem a seres desumanizados toda humanidade, toda possibilidade de compreensão, toda possibilidade de comunicação humana. Ver a colonialidade é tanto ver a aqui, a pessoa, o ser que está em um mundo de significado sem dicotomias, quanto a besta, ambas reais, ambas lutando por sobrevivência sob diferentes poderes (Lugones 2014: 946).

Há outras vertentes de defesa dos direitos dos animais, como aquela que trata de buscar reconhecimento dos animais como seres sencientes, ou seja, dotados de sensibilidade e consciência capazes de sentir as emoções tradicionalmente consideradas humanas, como medo, alegria, dor e sofrimento. Nesse sentido, o par racional-irracional que historicamente vem sendo utilizado para o tratamento elementar de distinção entre humanos e não humanos é restruturado a partir da categoria do agir comunicativo, de uma perspectiva de atribuição de léxicos, sentidos e de buscar romper assimetrias por meio das formas de compreensão da ideia de comunicação. Dessa forma, pesquisas recentes têm buscado estabelecer métodos de compreensão das formas comunicativas intra-animal e também entre humanos e animais. Nessa vertente, a defesa de suas vidas passa pelo argumento de que um ser vivo não deveria possuir o direito nato de colonizar a outro ser vivo, para trabalho ou para comensalidade, de forma que a perspectiva abolicionista se torna referência retórica para a construção da defesa da vida dos animais.

No caso do debate sobre degradação ambiental, há ainda a emergência do veganismo como uma das formas possíveis de resistência ao diagnóstico da catástrofe ambiental contemporânea, assentada em dados de pesquisa que correlacionam as formas de produção e reprodução da vida material humana com comensalidade e degradação ambiental da água e do solo (Stengers 2014: 1). Dessa perspectiva, o desmatamento e a degradação do solo, estruturados para suprir a demanda pelo consumo de carne a partir da criação de gado, além da quantidade de água necessária para manutenção das fazendas e a liberação de gás metano e $\mathrm{CO} 2$ por parte dos animais se tornam fatores responsáveis pela degradação ambiental e instabilidades climáticas que colocam em risco todas as vidas e, principalmente, a vida humana, o que reposiciona o humano como elemento central no argumento da luta pela vida.

Contrariamente, pensar a sobrenatureza da catástrofe implica concebê-la como resultado de uma 'guerra dos mundos' (Latour 2002), quero dizer, uma guerra entre guerras (penso certamente na guerra de Estado e sua magia negra, mas também nas guerras contra o Estado, por exemplo, na guerra xamânica dos índios contra os brancos na guerra Epidêmica dos animais contra os humanos, enfim, na guerra de Gaia contra a Civilização) - conflito esse em que humanos e não humanos, vivos e não vivos, espíritos e máquinas, se imaginam e contra-imaginam uns aos outros, segundo economias heterogêneas e mesmo incomensuráveis de alteridade. E, como diz Mauro Almeida a respeito da guerra entre Caipora e o Estado, 'não se trata de conflitos culturais, e sim de guerras ontológicas, porque o que está em jogo é a existência de entes no sentido pragmático. É a questão de vida e de morte para Caipora, para antas e macacos, para gente-de-verdade e para pedras e rios' (Almeida 2013: 22; Valentim 2014: 7). 
Dessa forma, o debate sobre comensalidade, sobretudo no caso do veganismo, criticado pelo caráter elitista, uma vez que demanda rearranjos dos usos do tempo na esfera doméstica, trabalho que usualmente recai sobre as mulheres, aparece como solução individual para frear a produção de carne a partir do consumo, recaindo no problema da individualização como solução para problemas políticos e sociais. No caso do Brasil há ainda um agravante: desde uma perspectiva racial é possível perceber também como a alimentação vegana foi utilizada como retórica de defesa dos direitos dos animais, e que acaba revelando uma estratégia política de perseguição a religiões de matrizes africanas. As negociações entre ecologia, gênero, raça e religião ocorrem, no caso do Curdistão, como plano de política pública e coletiva, cuja individualidade expressa-se a partir do caráter consensual das demandas produzidas no conjunto da política.

O importante aqui é perceber as construções das diferentes narrativas de defesa da terra e da Terra, defesa da vida humana e não humana. Assim, a politização das teorias sobre o antropoceno, ainda que estejam em construção, parecem buscar uma crítica combinada da constatação do estado de degradação ambiental em âmbito terrestre e as vertentes que realocam a ideia de vida associada à própria forma de produção e reprodução da vida humana e não humana, orientada por uma perspectiva de estabelecimento de relação não exploratória com o meio ambiente. E isso insere a ecologia, os novos arranjos de agricultura e a reorganização e manutenção da vida coletiva em função de estabelecer novos parâmetros para o estabelecimento de uma pauta política conjunta no que diz respeito às demandas de temporalidade e pragmatismo da vida laboral e familiar comum.

Quando se trata da ideia de vida, no caso das vidas curdas, trata-se de existir livremente em seus mais variados modos de vida, religiosamente, culturalmente, espiritualmente etc. Nesse sentido, a noção de vida é caracterizada por sua plenitude e por uma perspectiva ontológica de justiça, e não apenas sobreviver. No caso de um povo que luta pelo reconhecimento internacional de que há um genocídio em curso, como os curdos, a defesa da vida não se trata apenas de uma questão identitária, o que por si só já seria suficientemente relevante; trata-se do compromisso político com sua existência.

Independentemente de como serão negociadas as relações entre os praticantes do zoroastrismo e os das variadas vertentes do islã no Curdistão, a espiritualidade compõe a agenda política, e com muita proximidade daquilo que vem se convencionando chamar nos movimentos sociais afro-ameríndios na América Latina de bom-viver. O conjunto analítico ecologia, gênero e etnicidade acaba produzindo novos parâmetros ontológicos, para pensar as formas de relação entre humano, não humano e Terra a partir de cosmologias que tratam de questões inalcançadas pela tradicional epistemologia moderna e liberal. Assim, a sentimentalidade coletiva sobre a espiritualidade ou sobre conjuntos de crenças consideradas como sendo da ordem do sagrado passam a ocupar papel central de mediação das relações que reorganizam a própria ideia de vida.

É obvio que o pano de fundo dessa discussão é o fato de que a superação das Dicotomias modernas (sujeito e objeto, organismo e ambiente, cultura e natureza etc.) implica a reconceituação de organismo, vida, lócus da agência e da senciência, atmosfera e morte (Taddei 2014: 2). 
As aproximações entre os diálogos de ecologia e os movimentos sociais e políticos da periferia do capitalismo também aparecem na discussão sobre alter geoengenharia apresentado por Renzo Taddei (Taddei, 2014), no qual ele realiza uma discussão sobre a retórica científica moderna sobre meteorologia, utilizando os escritos de David Kopenawa, e a atuação da instituição afro-umbandista Fundação Cacique Cobra Coral (FCCC), que afirma controlar fenômenos atmosféricos por meio de rituais religiosos. Taddei descreve um número considerável de eventos nacionais (como a chegada do Papa Francisco ao Brasil, o réveillon no Rio de Janeiro ou o Rock in Rio), no qual os centros nacionais de meteorologia atuaram em conjunto com a FCCC para realizar o trabalho espiritual de desvio das chuvas torrenciais iminentes para regiões áridas. Para além da descrição dos vínculos das instituições indígenas e da FCCC com o poder público nacional, Taddei reforça a necessidade de repensar se as relações ontocosmológicas latino-americanas de fato tratam de reiterar a crítica à ocidentalidade europeia moderna, ou se tratam de incorporá-la ao trabalho espiritual ontológico vigente, criando uma forma de superação dessas relações binárias.

É possível assinalar que a necessidade do movimento de transcendência da relação sujeito-objeto, conforme descrito por Donna Haraway (1995: 21), e de organizar uma agenda política contra-hegemônica e pós-colonial é apontada como caminho nos diálogos sobre a politização da ecologia e nos feminismos pós-coloniais. A questão que se coloca agora seria como traduzir esse movimento para uma agenda política e de pesquisa com a possibilidade de construção de categorias conjuntas, incorporando diferentes perspectivas de vida em suas distintas percepções sobre espiritualidade e inter-relacionadas às noções de gênero e etnicidade.

\section{Ecologia, etnicidade e gênero na pauta do projeto nacional curdo}

A aproximação entre os diálogos sobre o antropoceno, perspectivismo, debates de gênero e questão curda não é uma novidade, haja vista que o epílogo do último livro do cientista político e líder independentista curda Abdullah Öcalan, intitulado “Confederalismo Democrático" (2016), é assinado pelo antropólogo Eduardo Viveiros de Castro. Para além da semelhança da perspectiva de uma minoria étnica estabelecendo parâmetros políticos de resistência anticolonial e antiestatal, além das referências e inspirações anarquistas, o projeto nacional que vem se desenvolvendo pelos movimentos políticos curdos busca, por meio do exercício do direito de autodeterminação dos povos e autonomia política e territorial, estabelecer um projeto de independência dos Estados nacionais que dividem as fronteiras de seu território. $O$ projeto de autonomia curda passou por diversas etapas nos últimos 40 anos, sendo que a principal delas é marcada pela defesa da incorporação dos debates de gênero para a própria pauta da nação nas duas últimas décadas.

Os curdos, também conhecidos como povos das montanhas, têm sido apontados como a principal perspectiva de esperança democrática no atual estado dos conflitos no Oriente Médio. A passagem de movimentos de luta e resistência unificados para a consolidação de um projeto político foi possível a partir dos inúmeros trabalhos que buscavam descrever e compreender as diversidades inscritas no in- 
terior dessas comunidades à exaustão. Para além das dinâmicas internas das comunidades, a ciência de que boa parte dos conflitos do Oriente Médio são resquícios do colonialismo britânico e francês e da luta pelo controle do petróleo na região fez que com a pauta ambiental e a reorganização cotidiana da vida também fossem incorporadas como centrais ao projeto nacional. Essa centralidade, como foi dito no início deste texto, não trata apenas de alinhar paralelamente as demandas das mulheres, das comunidades curdas ou da defesa do território; trata-se, pois, de criar um modelo político produzido coletivamente, que propõe que a implementação da igualdade de gênero na vida social e na política requer a restruturação da própria noção de vida e as formas de organizações das relações sociais, culturais, de trabalho, matrimoniais, econômicas como caminho a ser trilhado conjuntamente por homens e mulheres.

Flávia Xavier Merlotti Panizé doutoranda no Programa de Pós-Graduação em Sociologia, IFCH, Unicamp.

\section{REFERÊNCIAS BIBLIOGRÁFICAS}

AL-ALI, Nadje; PRATT, Nicola. 2011. "Between nationalism and women's rights": the kurdish women's movement in iraq. Middle East journal of culture and communication: Leiden. pp. 337-353.

BOZARSLAN, Hamit. 2007. “La question Kurde. États, minorities au Moyen-Orient”. Paris: Presses de la fondation nationale des Sciences Politiques.

COSTA, Alexandre Araújo. 2014. “Sobre Crise Ecológica, Violência e Capitalismo no Século XXI”. Anais de eventos: Os mil nomes de Gaia, Rio de Janeiro.

DANOWSKI, Déborah; VIVEIROS DE CASTRO, Eduardo. 2015. Há mundo por vir? Ensaios sobre os medos e os fins. São Paulo: Instituto Socioambiental.

DONOVAN, Josephine. 1990. “Animal Rights and Feminist Theory”. Signs 15 (2): 350-375.

VALENCIA, Érika Carcaño. 2008. “Ecofeminismo y ambientalismo feminista. Una reflexión crítica”. Argumentos 21 (56), México ene./abr.

ESBORRAZ, David Fabio. 2016. "El modelo ecológico alternativo latinoamericano entre protección del derecho humano al medio ambiente y reconocimiento de los derechos de la naturaliza”. Rev. Derecho Estado n $^{\circ} .36$ Bogotá Jan./June.

FAUSTO, Juliana. 2014. "Os desaparecidos do Antropoceno". Anais de eventos: Os mil nomes de Gaia, Rio de Janeiro.

FLACH, Anja. 2007. Frauen in der kurdischen guerilla: motivation, identität und geschlechterverhältnis in der frauenarmee der pkk. Köln: papyrossa publishers.

GIRALDO, Omar Felipe. 2014. “Utopías en la era de la supervivencia. Una interpretación del Buen Vivir”. Polis 14 (40), Editorial Itaca, México D.F.

GUNES, Cengiz. 2012. The Kurdish National Movement in Turkey: From protest to resistance. London 
e New York: Routledge publishers.

HAIDAR, Victoria; BERROS, María Valeria. 2015. "Hacia un abordaje multidimensional y multiescalar de la cuestión ecológica: La perspectiva del buen vivir". Revista Crítica de Ciências Sociais n.108. KOWARSCH, Kilic. 2007. Psychological consequences of trauma experiences on the development of kurdish migrant women in the european union. Final results and background of a survey in five european countries and Turkey. Rotterdam: International free women's foundation.

LOZADA, Ricardo Andrés. 2016. "O sistema internacional no antropoceno". Revista Brasileira de Ciências Sociais 31 (92).

LUGONES, María. 2014. “Rumo a um feminismo descolonial”. Estudos Feministas, 22(3): 935-952. MINA ROJAS, Charo; MACHADO, Marilyn; BOTERO MOSQUERA, Patricia; ESCOBAR, Arturo. 2015. "Luchas del buen vivir por las mujeres negras del Alto Cauca”. Nómadas, n’.43.

MOJABI, Shahrzad. 2001. "The solitude of the stateless: kurdish women at the margins of feminist knowledge". In: Women of non-state nation: the kurds. Mazda publishers, pp.1-22.

NODARI Alexandre. 2014. "Limitar o limite: modos de subsistência”. Anais de eventos: Os mil nomes de Gaia, Rio de Janeiro.

ÖCALLAN, Abdullah. 2008. Guerra e paz no Curdistão. Perspectivas para uma solução politica da questão curda. International initiative freedom for abdullah ocalan- peace in kurdistan, Köln.

ÖCALLAN, Abdullah. 2016. Confederalismo Democrático. Rio de Janeiro: Editorial Rizoma.

ROMANO, David. 2006. The Kurdish Nationalist Movement Opportunity, mobilization, and identity. New York: Cambridge University Press.

STENGERS, Isabelle. 2014. "Gaia, the Urgency to Think (and Feel)". Anais de eventos: Os mil nomes de Gaia, Rio de Janeiro.

TADDEI, Renzo. 2014. “Alter geoengenharia”. Anais de eventos: Os mil nomes de Gaia, Rio de Janeiro. VALENTIM, Marco Antonio. 2014. “A sobrenatureza da catástrofe”. Anais de eventos: Os mil nomes de Gaia, Rio de Janeiro.

VIVEIROS DE CASTRO, Eduardo. 2010. Metafisicas canibales. Lineas de antropología pós estructural. Buenos Aires/ Madrid: Katz Editores. 


\section{MULHER, VIDA E LIBERDADE: GÊNERO, ETNICIDADE E ECOLOGIA NO MOVI- MENTO DE MULHERES CURDAS EM ROJAVA}

Resumo: O presente artigo busca apresentar um debate sobre as articulações entre gênero, etnicidade e ecologia nos movimentos organizados de mulheres curdas, situados majoritariamente no território declarado autônomo conhecido como Kobane, na Região Norte da Síria. No texto, apresentarei uma breve trajetória dos movimentos de luta pela autonomia do Curdistão ao longo do século XX e as negociações das categorias de igualdade de gênero, que vem sendo mobilizada e promovida pelo movimento de mulheres curdas como pilar do movimento de fundação de uma nação curda. Como conclusão, apresentarei uma reflexão sobre como o lema Jîn, Jîan e Azadî (mulher, vida e liberdade, respectivamente), que orienta as perspectivas de restruturação da vida produtiva e reprodutiva das mulheres curdas, e como esse processo pode dialogar com os debates do campo da ecologia e dos feminismos pós-coloniais produzidos a partir de estudos e reflexões sobre diferentes comunidades indígenas e quilombolas na América Latina.

Palavras-chave: questão curda, gênero, ecologia, Oriente Médio

\section{WOMEN, LIFE AND FREEDOM: GENDER, ETHNICITY AND ECOLOGY IN THE KUR- DISH WOMEN'S MOVEMENT IN ROJAVA}

Abstract: The present article seeks to present a debate on the articulations between gender, ethnicity and ecology in the movements organized by Kurdish women, located mostly in the self-declared autonomous territory known as Kobane, in the North Syria Region. In the text I'll present the trajectory of the Kurdish movements struggling for autonomy in the XX century and the negotiations of the categories of gender equality, which have been mobilized and promoted by the Kurdish women's movements as the ground floor of the movement for the foundation of a Kurdish nation. As conclusion, I'll pose a reflection on how the slogan "Jîn, Jîan Azadî" (women, life, freedom, respectively) guides the perspectives of restructuration of Kurdish women productive and reproductive life and how this process might be used to compose a dialogue with the debates around ecology and post-colonial feminisms, produced based on studies and reflections on different indigenous and quilombolas communities in Latin America.

Keywords: Kurdish question, gender, ecology, Middle East

RECEBIDO: $04 / 10 / 2018$

APROVADO: 04/03/2019 